Reeve, D. (2000) 'Oppression within the counselling room', Disability \& Society 15(4): 669-682.

This is the corrected version incorporating reviewer comments and has been paginated to match the published version. Small typographical differences may therefore exist between this and the published version.

\title{
STUDENT PERSPECTIVES
}

\section{Oppression Within the Counselling Room}

\author{
DONNA REEVE \\ Disability Research Unit, University of Leeds, Leeds LS2 9JT, UK
}

\begin{abstract}
This paper suggests that the oppression experienced by disabled people in society is sometimes replayed in the counselling room by counsellors who are unaware of their own disablist attitudes and prejudices. Whilst the provision of Disability Equality Training (DET) within counselling courses would ameliorate the problem, I believe that disabled people would be most empowered by a counselling approach which recognises the potential for oppression within the counsellor-client relationship. One solution may be the creation of a new counselling approach, disability counselling, which includes the social model of disability as one of the foundations. An alternative solution may be found within the emerging counselling approaches that treat counselling as a social and political process and place emphasis on developing comprehensive anti-discriminatory practice.
\end{abstract}

\section{Introduction}

This paper examines closely the counselling relationship between a counsellor and their disabled client, and considers the nature of the power in that relationship. My own personal experiences as a disabled client and counsellor have led me to question the nature of that relationship, and to try and place it in context with the relationship between disabled people and a disabling society.

Counsellors are subject to the same negative images and stereotypes of disabled people as the rest of society. The attitudes and prejudices of counsellors towards disabled people can adversely affect the nature of the client-counsellor relationship when the client is a disabled person - there is sometimes oppression within the counselling room. Whilst counsellors are aware of the need to challenge their racist and sexist attitudes, I will suggest that many counsellors are unaware of their disablist attitudes which remain unrecognised and unchallenged. This is due to the fact that Disability Equality Training (DET) is missing from most counselling courses and to the dearth of disabled people training as counsellors. Disability is not present as an issue on these courses in the same way that race and gender are.

Whilst the provision of DET would make counsellors aware of disability as a social construction, rather than individual tragedy, I do not see that it can go far enough in providing counselling which is empowering for disabled people. I suggest two possible solutions that recognise the potentially oppressive nature of counselling and seek to redress the power imbalance. The first solution builds upon transcultural counselling creating a new counselling approach called disability counselling that 
recognises oppression within the counselling room and incorporates the social model of disability as a cornerstone. The second solution draws attention to new counselling approaches which adopt a social and political, rather than a psychological stance. These new approaches aim to achieve comprehensive anti-oppressive practices that offer empowering counselling for all people, irrespective of race, gender, religion, class or disability.

\section{Background}

The most common psychological theories designed to explain personal responses to disability are based on the assumption that there will be psychological adjustment as the individual comes to terms with their impairment. This assumption has been added to by various grief and stage theories (Oliver, 1995), which predict that disabled people are expected to grieve, mourn and express feelings of anger and denial, before they can become psychologically whole again (Lenny, 1993). There have been many criticisms of these 'loss' theories that attempt to explain how people respond to disability (Lenny, 1993; Oliver, 1995). The suggestion that disabled people will inevitably need to adjust to this change leads to the assumption that becoming disabled is psychologically devastating and that such a personal tragedy can only be resolved by grieving the loss (French, 1994). These assumptions are the

product of the 'psychological imagination' constructed upon a bedrock of 'nondisabled' assumptions of what it is like to experience impairment (Oliver, 1996: 21)

and arise from the medical model of disability in which impairment is seen as the cause of disability and posits disability as an individual tragedy (Bury, 1997).

These 'loss' theories have been heavily criticised for not taking into account the social dimension of disability by assuming that the only response will be one of personal loss (Oliver, 1990). When a person acquires an impairment or becomes chronically ill then their lives will be changed in some way; for some people, the experience of impairment can cause feelings of loss in areas such as changes in bodily function or future life choices, and so a bereavement or 'loss' theory might be appropriate in this case. For most disabled people, the real problems, such as losses within work or social life, come from living in a disabling environment, rather than the experience of impairment (Oliver, 1995). This fact supports the social model of disability in which disability is caused by 'externally imposed disadvantage and social restriction' (Oliver and Barnes, 1998: 18), rather than impairment. The 'loss' theories which claim to explain personal responses to disability do not explain the emotional distress experienced by disabled people living within a disabling environment.

The assumption that becoming disabled is psychologically devastating also implies that all disabled people will therefore need counselling to come to terms with their 'losses' (Lenny, 1993). This is given credence by the negative stereotypes of disabled people as bitter and self-pitying because of an individual failure to 'accept' their disability (Oliver, 1990). Whilst there is limited evidence for the validity of 
these 'loss' theories (Robertson, 1992), they are still presented in the counselling literature as the only way that people respond psychologically to disability. Not all disabled people want counselling (Lenny, 1993), but those that do decide to seek counselling want access to counselling services which meet their perceived needs (McKenzie, 1992); person-centred counselling with its lack of assumptions about how people respond to disability is seen by some to be the least intrusive counselling approach, when compared with psychodynamic and behavioural approaches (Lenny, 1993).

Many of the issues which disabled people might seek counselling for are common to all people in society - marriage problems, stress, childhood traumas, etc. However, disabled people may also have additional difficulties which they may try to resolve through counselling such as experience of the medical profession (Oliver, 1995), living with pain and exhaustion (Crow, 1996), internalised oppression (Keith, 1996) and the experience of living in a disabling society. It is very important to be clear about what counselling can achieve and what it cannot. Counselling cannot fix disability because disability is a problem created by society and not the individual, although it can help someone to explore the ways in which they are being disabled and how they feel about it (Lonsdale, 1990).

I also want to recognise that disabled people who do decide to seek counselling have less choice than is available to non-disabled people. Some charities such as the Multiple Sclerosis Society (Lewis, 1999) and Spinal Injuries Association (SIA, 1998) provide free face-to-face and telephone counselling to people with these specific impairments. However, lack of accessibility in the built environment generally, together with the fact that disabled people are a financially disadvantaged group within society (Barnes, 1991) means that counselling is not available to many disabled people. My personal experience indicates that counsellors in private practice or within agencies which are not related to disability, do not see many disabled clients. As a result, the mistaken conclusion is made that disabled people do not want to use their services and little effort is made to meet the access needs of this particular client group.

The rest of this paper will consider more closely the nature of the relationship between a disabled person and the counsellor (non-disabled or disabled). I will explore how the experience of living within a disabling society can be replayed within the counselling room and suggest two solutions to this problem. Corker (1995) writes about counselling from the perspective of both a deaf person and a counsellor; her comments about oppression within the counselling room together with my own personal experiences as a disabled person, both client and counsellor, are the starting point for the ideas I will now present.

\section{Oppression in the Counselling Room}

The British Association for Counselling (BAC), which is the largest counselling organisation in the UK, describes counselling as:

an opportunity for the client to work towards living in a way he or she 
experiences as more satisfying and resourceful ... the counsellor's role is to facilitate the client's work in ways which respect the client's values, personal resources and capacity for choice within his or her cultural context. (BAC, 1998: 8).

The question I now want to consider is whether or not disabled people have access to counselling that meets this description - is the experience of counselling empowering or oppressive?

\section{The Counsellor-Client Relationship}

Within counselling the 'core conditions' offered by the counsellor - empathic understanding, unconditional acceptance and genuineness - are considered to be the essential minimum for a working alliance between the counsellor and client (NelsonJones, 1982). A healthy counselling relationship occurs when the counsellor-client relationship is one of partnership and equality (Corker, 1995). This requires the counsellor to be aware of, and work with the inherent power imbalance between the 'trained' counsellor and 'vulnerable' client. Counsellors who follow the BAC Code of Practice are reminded that they have

a responsibility to consider and address their own prejudices and stereotyping attitudes and behaviour and particularly to consider ways in which these may be affecting the counselling relationship and influencing their responses.

(BAC, 1998: 10).

Counsellors, like all other people in society, are fed a stream of negative images and stereotypes of disabled people from a very early age, which contributes to the continued discrimination and exclusion of disabled people within society (Shakespeare, 1994). Whilst counsellors understand the need to address their own sexist and racist attitudes, I believe that many of them fail to consider their own prejudices and assumptions about disabled people. As a result these counsellors themselves are part of an oppressive culture (Corker, 1995) and such counsellors who are unaware of their disablist attitudes may further oppress their disabled clients within the counselling room. A similar process has been observed in a study of GPs and the way in which they oppressed their disabled patients because they had not tackled their own negative attitudes towards disabled people (Begum, 1996). My personal experience of being a disabled client, together with anecdotal evidence from disabled friends who have also experienced counselling, has led me to conclude that this oppression can be a reality in some (but not all) counsellor-client relationships where the counsellor is non-disabled. Examples of oppression include assumptions by the counsellor that relationship problems are totally caused by the presence of impairment, disbelief that a disabled client would consider refusing surgical intervention to be 'normalised', as well as relocating a counselling session to an inaccessible room (Withers, 1996).

I would like to consider two reasons why counsellors may be unaware of their own prejudices and stereotypes of disabled people. The first reason is that basic 
counselling training courses are primarily designed to teach counselling skills and theory (Lago and Thompson, 1996). As a result very little time, for example 1 day in a 2 year Diploma course, is spent making counsellors aware of equal opportunities and how it should inform their practice. Whether or not disability equality is included within this area is a moot point - even BAC accredited courses only have to comply with the requirement that courses include reference to the effect of factors such as 'race, culture, gender, sexuality, politics, religion, ethics and class' (BAC, 1996: 8) disability is missing from the list. I believe that it is vital that all counsellors (from trainee to supervisor and tutor) have Disability Equality Training (DET) to raise their awareness of how their own attitudes can disable people. A request for a disability component in counselling training was also raised by all of the participating counsellors in the study by Oliver (1995). Unfortunately, my personal experience is that some counsellors believe that they already 'unconditionally accept all people' and therefore don't need DET (a feedback comment from a DET course I gave to counselling students). It is important that counsellors understand disability as a social construct and the ways in which disabled people are systematically excluded from participating in everyday life.

If counsellors can move away from the viewpoint of disability as an individual 'problem' with the assumption that it has a negative impact on that person's life (medical model perspective), then other benefits for disabled clients would follow. Counsellors who understand the distinction between impairment (medical condition) and disability (social oppression) would no longer consider the 'loss' theories described previously to be applicable - they would lose credibility as a total description of how people respond to disability. In addition, I would hope that these 'enlightened' counsellors would take on personal responsibility for making their counselling services more accessible for disabled people.

As well as including DET, counselling courses also need to teach counsellors to be more imaginative and flexible when counselling disabled people (Oliver, 1995). Part 3 of the Disability Discrimination Act regarding access to services came into effect in October 1999; this means that counselling agencies will need to make their information available in accessible formats, provide access to a sign language interpreter, as well as overcome the problems posed by inaccessible premises by using home visits or telephone counselling (DN, 1999). This is especially true of specialist agencies such as drug and alcohol projects, which need to be available to disabled and non-disabled people alike. Few counselling services offer home visits because of the issues about the personal safety of the counsellor (Nicholas, 1992). This problem can be solved by the use of telephone counselling which can be as effective as face-to-face counselling if counsellors are properly trained (Sanders, 1996). However, this solution will not be appropriate for all disabled people and the question of home visits will need to be explored further. Counsellors need to be trained in the use of a minicom for counselling deaf clients over the phone (Corker, 1995). Counsellors who are not fluent in BSL will need to adapt to the particular challenges of working with a Deaf client and sign language interpreter within the counselling session (Corker, 1995). Finally, there are a range of issues that a 
counsellor needs to be aware of when counselling people with communication difficulties to avoid misunderstandings (Brearley and Birchley, 1994).

\section{Disabled Counsellors}

The lack of DET provision on counselling courses is one reason why counsellors are unaware of their prejudices about disabled people. A second reason, I would suggest, stems from the fact that there are very few disabled people going through counselling training to become counsellors (Withers, 1996). As a result disability is not present 'in the room' as an issue in the same way that race and gender are. Many disabled people who train as counsellors experience difficulties with tutors (and fellow students) who are prejudiced, and as a result come up against pity, anger, embarrassment and other disabling conditions (Withers, 1996). A revealing article describing the personal experiences of a deafened counselling trainee and her tutor showed how frequently the trainee was excluded from the group by both the tutor and her peer group (Monks and Martin, 1997). During my own training I experienced exclusion, and denial of my difference by tutors and students, which I found very oppressive and frustrating. In addition to these difficulties, counselling training is expensive. This, together with inaccessible course materials and venues for skills practice, means that many disabled people with the potential to become competent counsellors are excluded from counselling courses. Finally, many counselling courses require that the counsellor be receiving counselling themselves. Cost and lack of access can make it very difficult for disabled counselling students to meet this particular course requirement.

The process of oppression of disabled clients by non-disabled counsellors can also be repeated in the supervision relationship between a disabled counsellor and nondisabled supervisor (Corker, 1995). As a disabled counsellor I have also experienced the frustrations of having a supervisor who is unwilling to acknowledge the difficulties which occur when a disabled counsellor experiences oppression from non-disabled clients within the therapeutic relationship. The dearth of professionally trained disabled counsellors means that there are even fewer disabled supervisors especially so for Deaf counsellors who want to work in BSL (Ratna, 1994).

There has been some discussion about whether or not disabled counsellors should counsel disabled people. A disabled person may want to request a counsellor who is also disabled, maybe even with the same impairment - it is not unusual for a black client to request a black counsellor or a gay client to feel more comfortable with a gay counsellor. However, because of the scarcity of disabled counsellors, the reality is that disabled people have less choice about whether they see a disabled or nondisabled counsellor. Disabled people may want a disabled counsellor because of the 'shared' experience of disability. Many disabled clients, myself included, find that they have to educate their counsellor about their reality of living in a disabling society (Withers, 1996). Alternatively, they may prefer a non-disabled counsellor because of internalised oppression creating the belief that a disabled counsellor could not be as good as a non-disabled one (Ratna, 1994). There are mixed views on whether disabled counsellors should counsel disabled people (Oliver, 1995). I 
believe that both disabled and non-disabled counsellors can counsel disabled people as long as they are aware of the potential problems such as over-identification and work with these in supervision. It is also vital that both non-disabled and disabled counsellors are aware of their own disablist attitudes and prejudices - being disabled does not automatically exempt someone from oppressing other disabled people.

I have shown how disabled people who do manage to find a counsellor who is accessible, may find the experience to be an oppressive one because of counsellors who are unaware of their own prejudices and attitudes towards disabled people. The addition of DET into counselling courses is one way of reducing oppression in the counselling room for disabled clients. Certainly counsellors (and supervisors) who understand disability as a social construct are most likely to enable their clients towards self-empowerment. I would also like to see more disabled people becoming counsellors so that disability remains a 'live' issue on counselling courses.

Unfortunately, I do not believe that this will be sufficient to ensure that the experience of counselling for a disabled person is always one which empowers, rather than oppresses. Whilst DET should be a mandatory part of all counselling courses, I agree with another counsellor who states:

But I don't think that in itself is enough. What worries me is that people think, 'well, I've done that therefore I must have the kit'. (S5 in Oliver, 1995: 269).

If DET for counsellors alone is not sufficient to ensure that counselling is a positive experience for disabled people, then what else needs examination? Oliver (1995) states that disabled people do not need different counselling to non-disabled people. I can only agree with this up to a point because I believe that the counselling relationship itself can oppress disabled clients more than non-disabled clients and that DET alone is not enough to prevent this happening. I now want to look more closely at recently developed counselling approaches that address the needs of other minority groups in society and see if they have anything to offer disabled people.

\section{Future Directions: Naming the Oppression}

One of the criticisms of counselling has been the way in which counsellors, who are usually white, middle class, heterosexual and non-disabled (McLeod, 1998), have continued to ignore the social injustices experienced by their clients (Masson, 1992). If counselling is not going to become part of the problem for people who are oppressed then I believe that counsellors need to act as agents of social change because

counselling is a 'social enterprise' and cannot be divorced from the social, economic and political environment in which it is practised. (Woolfe et al., 1989: 11).

Psychodynamic, behavioural and person-centred counselling form what is historically known as the first wave of counselling approaches (McLeod, 1998). These approaches paid little attention to the issue of power or the social role of counselling. 
The second wave of counselling approaches including feminist and transcultural counselling do recognise the potentially oppressive aspects of counselling. I now want to look at transcultural counselling to consider if this approach which openly acknowledges oppression within the counselling relationship has anything to offer counsellors working with disabled people.

\section{Recognition of Oppression: Transcultural Counselling}

Over the last 15 years there has been an increasing awareness of the importance of cultural differences between counsellor and client, and the effect this has on counselling practice (McLeod, 1998). Transcultural counselling actively addresses the issues of cultural difference between counsellor and client, particularly the racial and cultural prejudices of the counsellor, and how they affect the counsellor-client relationship (d'Ardenne and Mahtani, 1989). Corker (1995) explores at length the link between transcultural counselling, and the counselling scenario where the counsellor is hearing and the client deaf. Deaf people are part of a linguistic and cultural minority; like Black people they share common cultural experiences and history of oppression, which makes transcultural counselling a natural choice. Transcultural counsellors also recognise the importance of cultural differences in areas such as non-verbal communication and the expression of strong feelings. These areas cause misunderstandings for deaf clients where emotions may be over-interpreted by a hearing counsellor; for example irritation or annoyance may be incorrectly interpreted as anger (Corker, 1995). Many of the issues which are covered by transcultural counselling, such as the reality of prejudice and discrimination in the life of the client (Lago and Thompson, 1996), are also appropriate issues to consider when working with disabled clients.

The question I now want to consider is whether transcultural counselling can be applied generally to the situation of counsellors working with disabled clients because in the majority of counselling services the counsellor will be non-disabled and, therefore, from a different 'culture'. This 'cultural difference' is particularly true for the scenario when a hearing counsellor is working with a Deaf client; such a client defines themselves as a member of a linguistic and cultural minority group, rather than being disabled (Corker, 1998). Whilst transcultural counselling is applicable to this example, I am not confident that transcultural counselling as it stands would provide the complete solution for counsellors working with disabled clients generally. Disabled people are not a homogenous group, are likely to be isolated and separated from each other, living within a community or family of non-disabled people. This is quite different to the case for people from different cultures where there will usually be role-models within the family and community who can give support (Shakespeare, 1996).

However, transcultural counselling (unlike person-centred counselling) does at least recognise that counsellors live in a society in which discrimination and prejudice exists, and that it is essential that these people have to 
wards those who are culturally and racially different may well be, oversimplistic, judgemental and discriminatory. At worst and as a consequence, therapeutic aims may well have anti-therapeutic outcomes. (Lago and Thompson, 1996: 8).

If the words 'culturally and racially different' are replaced with 'disabled' then the statement supports my earlier observations on oppression in the counselling room by counsellors who are unaware of their own prejudices towards disabled people. The question I now want to consider is whether it would be possible to develop a new counselling approach based on the ideas of transcultural counselling.

\section{Disability Counselling: A New Approach?}

Transcultural and feminist counselling are established counselling approaches with oppression at their root, which were created from within the respective oppressed groups. I am suggesting that maybe it is now time to consider a separate 'disability counselling' approach which is developed by disabled people and has the social model of disability as one of the core supports, specifically disability as oppression. With the social model of disability at the centre, disability counselling, like feminist and transcultural counselling, would be 'profoundly social and political as well as personal and individual ' (Chaplin, 1988: 4). This approach would openly challenge disablist prejudices and attitudes in the same way that transcultural counselling challenges institutionalised racism within the counsellor.

Like transcultural counselling, disability counselling will be aware of the connection between social context and personal problems. A disability counsellor would be expected to look at disability from the social model point of view and to help disabled clients move away from blaming themselves for being socially excluded. A study involving disabled and non-disabled counsellors working with disabled clients showed that comments made from a social model perspective were the most effective ways of enabling clients to empower themselves:

Do you get angry at yourself or do you get angry with other things and other people and say 'help me change this situation so that I can get out'? (S8 in Oliver, 1995: 274).

Disabled people learn about the social model of disability from other disabled people and I do not see that disability counselling should be exempt from this process. On a warning note, it will be important to keep the line drawn between education and evangelising and to appreciate that not all disabled people will want to see disability from a social model perspective. Whilst it is a fact that not all people with impairments consider themselves disabled (Shakespeare, 1996), I still feel that counselling offered from a position of the social model is preferable to ignoring the reality of oppression inside and outside the counselling room.

Disability counsellors need to be aware of the disabling consequences of prejudice and discrimination together with the ways in which these are maintained by cultural representations of disability (Shakespeare and Watson, 1997) - a failure to 
recognise this could result in the client being blamed for not 'getting better'. Internalised oppression must be recognised and its effects on the development of identity acknowledged (described in more detail by Corker, 1996). One example of the effect of internalised oppression, in a similar manner to internalised racism (Rose, 1997), is the feeling of hatred by a disabled client towards their disabled counsellor this transference coming from the disowned 'disabled part' of the client being projected onto the disabled counsellor. Like transcultural counsellors, disability counsellors would have awareness of their attitudes, together with information and knowledge about the disabling society, in addition to counselling skills (Lago and Thompson, 1996). I would also expect that training for this counselling approach would require a large emphasis on self-awareness work on the part of the counsellor to help uncover attitudes and beliefs about disabled people which have been instilled in counsellors since the first fairy stories of childhood.

Disability counselling could develop links with a 'psychology of disability' (Finkeistein and French, 1993) because disability counselling would enable disabled people to deal with their relationship between the experience of individual impairment and the experience of a disabling society (Lenny, 1993). Thomas (1999) introduces the concept of a psycho-emotional dimension of disability that originates from within oppressive social relationships. This concept has meaning for disability counselling in which the oppressive nature of the counsellor-client relationship is being considered. Finally, disability counselling might also overlap with the 'social model of impairment' which places importance on the subjective experience of impairment (Crow, 1996). Therefore, I would expect that areas of Disability Studies would play an important part in creating a counselling approach which is empowering for disabled people.

Disability counselling must not be seen as a way of recruiting new members for the disabled people's movement, but it does have its part to play in enabling disabled people to develop a positive sense of identity. Shakespeare (1996) describes how disability identity is composed of three aspects - political, cultural and personal. Part of the process of developing a personal disability identity is that of 'coming out', replacing a negative self-identification with impairment (medical model) with a positive self-identification with disability as social exclusion (social model). Whilst this can be achieved through the process of self-organisation which is a collective context, it can also occur through individual personal awakening. I believe that disability counselling can offer a way of facilitating this individual process of positive self-identification, and as a result empower the disabled client by 'opening up the possibility of changing one's world' (Shakespeare, 1996: 103).

Whilst I am advocating a new counselling approach for disabled people, I am aware of potential problems this would cause. Do we really want (or need) another way of differentiating between disabled and non-disabled people? Apart from the fact that many people with impairments do not identify as disabled, disabled people are not a homogenous group because of the huge diversity of impairment and experience. Disabled people, like all other people, are multifaceted - gender, class, race, sexuality, etc., also define identity (Shakespeare, 1996) - and it may not make sense to offer counselling which only recognises the disabled facet of a person. Over 
recent years there have been moves within the counselling world to develop counselling approaches that view counselling as a social, rather than psychological process. As a result these approaches have moved towards seeing people as unique individuals, rather than labelled according to issues such as race or gender. I now want to consider briefly if these emerging approaches have the potential to provide an alternative solution to that offered by a separate disability counselling approach.

\section{Including Disability Within New Social Approaches to Counselling}

The existence of many counselling approaches for different groups of people is an indicator of the difficulty of providing counselling in a manner which is genuinely empowering for all clients (McLeod, 1998). New approaches that see counselling as a social and political act aim to achieve anti-oppressive practices, and place emancipation and empowerment as the counselling goals. The 'user-friendly' approach is a set of principles for good practice which openly addresses issues such as the counsellor-client power imbalance, as well as challenging much of contemporary counsellor practice (McLeod, 1998). For the first time ever in a counselling text book, I found disability included within one of the principles of a 'general' counselling approach; this principle of the 'user-friendly' approach

4. Understands that users cannot be treated as though they were identical. Class, gender, sexual orientation, power, age, disability, ethnic origin, religion and socio-cultural background are some of the more obvious differences which need to be taken into consideration if successful therapy is to be undertaken. (McLeod, 1998: 259).

Therefore, I believe that these newer counselling approaches potentially have much to offer disabled people, as well as other oppressed and disadvantaged groups within society. Drawing much from transcultural counselling there is significant emphasis on counsellors being trained in areas which recognise the totality of human experience political, social and historical contexts, in addition to the psychological aspects. As a result I would expect counsellors using these principles when working with disabled people to have an understanding of the historical, material and cultural contributions which have created the condition of disability, and the ways in which this form of social oppression is maintained within our society. These social counselling approaches encourage the counsellor to treat the client as a unique human being, free from labels such as female, gay or disabled.

Whilst these social approaches to counselling are evolving I think that it is vitally important for disability, as socially created oppression, rather than individual tragedy, to be represented and included from the outset. In that way, these new counselling approaches are more likely to meet the needs of disabled people, rather than leaving it to other professionals to make assumptions on our behalf. There are very few counselling agencies who are adopting these innovative ways of counselling (McLeod, 1998), and these approaches are relatively new and untested. However, I would hope that the recognition of the dangers of oppression in a counselling 
relationship together with an emphasis on the social and political reality of all clients, disabled or not, offers a productive way forward for counselling generally.

It is not clear to me at this time whether disabled people will be best served by another monolithic counselling approach addressing the specific concerns of disabled people, or by one of the new emerging social approaches to counselling with their holistic view of clients as human beings. However, I do believe that the issue of disability as social oppression does need to be represented within counselling theories, now and not later. Otherwise, oppression within the counselling room will often continue, preventing disabled people from gaining benefit from counselling in the same way that non-disabled people do.

\section{Conclusions}

It has been recognised that disabled people need access to a counselling service which meets their perceived needs (Oliver, 1995). I have looked at the nature of the counsellor-client relationship to examine whether the counselling which disabled people receive is an empowering or oppressive experience. Counsellors, like the rest of society, are repeatedly bombarded by negative images and stereotypes of disabled people. Although counsellors readily acknowledge the importance of race and gender issues within the counselling room, I believe that the absence of DET from counselling courses together with the relatively small numbers of disabled people going through counsellor training, means that counsellors have little opportunity to look at their own unresolved prejudices and negative attitudes about disabled people. As a result, some counsellors can further oppress their disabled clients within the counselling room and counselling fails to be an empowering experience for the disabled client. DET is urgently needed for all counsellors; I would also like to see more disabled people becoming counsellors, and then on to become supervisors and tutors, challenging the system from the inside.

Whilst Lenny (1993) advocates the use of the person-centred approach for counselling disabled people I have argued that I do not think that this approach, even with DET, goes far enough in helping disabled people develop self-empowerment and a positive sense of identity. I believe that counsellors working with disabled people need to use a counselling approach that recognises the risk of oppression within the counselling relationship and therefore works to remove it. I have suggested two possible directions that could be taken to develop this approach. The first idea builds firmly on the principles of transcultural counselling which has oppression at its root, and suggests the creation of a new counselling approach - disability counselling - which has the social model of disability as a cornerstone. Counsellors working from this perspective would recognise the social constructions of disability. They could empower disabled clients by helping them move away from self-blame for being excluded and to develop a positive sense of identity by challenging their internalised oppression. Finally, I have considered some of the new counselling approaches which operate on a social and political level, rather than a psychological level, such as the 'user-friendly' approach. Using one of these newer approaches counsellors working with disabled clients would appreciate the political, 
social and historical context of what it means to be disabled and would be better able to help the client achieve the counselling goals of emancipation and empowerment.

\section{REFERENCES}

d'Ardenne, P and Mahtani, A (1989) Transcultural Counselling in Action. London: Sage. BAC (1996) Recognition of Counsellor Training Courses. Rugby: British Association for Counselling.

BAC (1998) Invitation to Membership. Rugby: British Association for Counselling.

Barnes, C (1991) Disabled People in Britain and Discrimination: A Case for AntiDiscrimination Legislation. London: Hurst and Co. and BCODP.

Begum, N (1996) General practitioners' role in shaping disabled women's lives. In Barnes, C and Mercer, $G$ (eds) Exploring the Divide: Illness and Disability. Leeds: Disability Press. Brearley, G and Birchley, P (1994) Counselling in Disability and Illness. London: Mosby. Bury, M (1997) Health and Illness in a Changing Society. London: Routledge.

Chaplin, J (1988) Feminist Counselling in Action. London: Sage.

Corker, M (1995) Counselling - The Deaf Challenge. London: Jessica Kingsley.

Corker, M (1996) Deaf Transitions: Images and Origins of Deaf Families, Deaf Communities and Deaf Identities. London: Jessica Kingsley.

Corker, M (1998) Deaf and Disabled, or Deafness Disabled?. Buckingham: Open University Press.

Crow, L (1996) Including all of our lives: renewing the social model of disability. In Morris, J (ed) Encounters With Strangers: Feminism and Disability. London: Women's Press.

DN (1999) Caught by the act. Disability Now, April, 10.

Finkelstein, V and French, S (1993) Towards a psychology of disability. In Swain, J, Finkelstein, V, French, F and Oliver, M (eds) Disabling Barriers - Enabling Environments. London: Sage and Open University Press.

French, S (1994) The disabled role. In S French (ed) On Equal Terms: Working with Disabled People. Oxford: Butterman-Heinemann.

Keith, L (1996) Encounters with strangers: the public's responses to disabled women and how this affects our sense of self. In Morris, J (ed) Encounters With Strangers: Feminism and Disability. London: Women's Press.

Lago, C and Thompson, J (1996) Race, Culture and Counselling. Buckingham: Open University Press.

Lenny, J (1993) Do disabled people need counselling?. In Swain, J, Finkelstein, V, French, S and Oliver, M (eds) Disabling Barriers - Enabling Environments. London: Sage and Open University Press.

Lewis, J (1999) A case for specialist counselling. PRG News \& Views (BAC), 8: 13-15.

Lonsdale, S (1990) Women and Disability: The Experience of Physical Disability Among

Women. Basingstoke: Macmillan.

Masson, J (1992) Against Therapy. London: HarperCollins.

Mckenzie, A (1992) Counselling for people disabled through injury. In Social Care Research Findings, No. 19. York: Joseph Rowntree Foundation.

McLeod, J (1998) An Introduction to Counselling, 2nd edn. Buckingham: Open University Press.

Monks, P and Martin, L (1997) A deaf counselling trainee: can it work?. Counselling, 8: 263265.

Nelson-Jones, R (1982) The Theory and Practice of Counselling Psychology. London:

Cassell.

Nicholas, J (1992) The inside story: on seeing clients in their own homes. In Noonan, E and Spurling, L (eds) The Making of a Counsellor. London: Routledge.

Oliver, J (1995) Counselling disabled people: a counsellor's perspective. Disability \& Society, 10: $261-279$.

Oliver, M (1990) The Politics of Disablement. London: Macmillan. 
Oliver, M (1996) A sociology of disability or a disablist sociology. In Barton, L (ed) Disability and Society: Emerging Issues and Insights. Harlow: Longman.

Oliver, M and Barnes, C (1998) Disabled People and Social Policy: From Exclusion to Inclusion. Harlow: Addison Wesley Longman.

Ratna, H (1994) Counselling deaf and hard of hearing clients. Counselling, 5: 128-131.

Robertson, S (1992) Counselling adults with physical disabilities: a transitions perspective. In Robertson, E and Brown, R (eds) Rehabilitation Counselling: Approaches in the Field of Disability. Cheltenham: Stanley Thornes.

Rose, E (1997) Daring to work with internalised racism. Counselling, 8: 92-94. Sanders, P (1996) An Incomplete Guide to Using Counselling Skills on the Telephone, 2nd edn. Manchester: PCCS Books.

Shakespeare, T (1994) Cultural representation of disabled people: dustbins for disavowal?. Disability \& Society, 9: 283-299.

Shakespeare, T (1996) Disability, identity, difference. In Barnes, C and Mercer, G (eds)

Exploring the Divide: Illness and Disability. Leeds: Disability Press.

Shakespeare, T and Watson, N (1997) Defending the social model. Disability \& Society, 12 : 293-300.

SIA (1998) SIA Annual Review 1997 - 98. London: SIA.

Thomas, C (1999) Female Forms: Experiencing and Understanding Disability. Buckingham: Open University Press.

Withers, S (1996) The experience of counselling. In Hales, G (ed) Beyond Disability: Towards an Enabling Society. London: Sage.

Woolfe, R, Dryden, W and Charles-Edwards, D (1989) The nature and range of counselling practice. In Dryden, W, Charles-Edwards, D and Woolfe, R (eds) Handbook of Counselling in Britain. London: Routledge. 